\title{
ANALYSIS OF 34 CASES OF ENDONASAL ENDOSCOPIC DACRYOCYSTORHINOSTOMY- SURGICAL SUCCESS AND PATIENT SATISFACTION, A CASE SERIES, OUR EXPERIENCE
}

\author{
N. Gopinathan Pillai1, Binu Babu², Anjana Mary Reynolds ${ }^{3}$, Subadhra $S^{4}$ \\ ${ }^{1}$ Associate Professor, Department of Otorhinolaryngology, PIMSRC, Thiruvalla. \\ ${ }^{2}$ Assistant Professor, Department of Otorhinolaryngology, PIMSRC, Thiruvalla. \\ ${ }^{3}$ Assistant Professor, Department of Otorhinolaryngology, PIMSRC, Thiruvalla. \\ 4Junior Resident, Department of Otorhinolaryngology, PIMSRC, Thiruvalla.
}

\section{BACKGROUND}

ABSTRACT

The conventional treatment of dacryocystitis is external dacryocystorhinostomy. Its success rate varies from $80-98 \% .^{1-4}$ But patient's satisfaction was poor due to facial scar, disruption of medial canthus anatomy and dysfunction of lacrimal pump mechanism. Endoscopic DCR has neither facial scar nor any postoperative distortion of lacrimal pump mechanism and medial canthal anatomy.

The objective of this study is to assess the surgical success rate and patient's satisfaction after endonasal endoscopic Dacryocystorhinostomy (DCR).

Study Design- This study was done at Pushpagiri Institute of Medical Sciences and Research Centre, Thiruvalla, between January 2012 and August 2016. There were 34 patients included in this study. Females are more commonly affected than males. Unilateral cases are more than bilateral cases. Their age ranges from 13 - 83 years. Mean age is 35 years.

\section{MATERIALS AND METHODS}

Patients presented with epiphora or swelling below the medial canthus of eye with or without pain, mucopurulent regurgitation from the lacrimal sac into the eye on pressing the swelling. Five patients had concomitant deviated nasal septum, for which septoplasty was done along with DCR. The patency of nasolacrimal duct was assessed by syringing and diagnostic nasal endoscopy.

\section{RESULTS}

The success rate is comparable to other studies of endonasal DCR. The present study has a success rate of $97 \%$. Advantages of endonasal DCR are: (1) There is no facial scar; (2) Preservation of lacrimal pump mechanism; and (3) Retention of medial canthal anatomy.

\section{CONCLUSION}

Endonasal endoscopic DCR overcomes all the drawbacks of external DCR and it is rapidly gaining recognition as a primary modality of treatment for dacryocystitis. Its success rate and patient's compliance rate are cent percent.

\section{KEYWORDS}

Dacryocystitis, Endonasal Dacryocystorhinostomy, Epiphora, Facial Scar, Nasolacrimal Duct Obstruction.

HOW TO CITE THIS ARTICLE: Pillai NG, Babu B, Reynolds AM, et al. Analysis of 34 cases of endonasal endoscopic dacryocystorhinostomy- surgical success and patient satisfaction, a case series, our experience. J. Evolution Med. Dent. Sci. 2017;6(62):4522-4525, DOI: 10.14260/Jemds/2017/978

\section{BACKGROUND}

\section{Lacrimal Apparatus}

It consists of lacrimal gland, lacrimal canaliculi, lacrimal sac and nasolacrimal duct. Lacrimal fluid is produced by the lacrimal gland. The secretions drain through numerous ducts into superolateral conjunctival sac of the eye, from there it flows to the medial angle of the eye by the contraction of orbicularis oculi muscle. From the medial angle of eye, lacrimal fluid enters the superior and inferior canaliculi through lacrimal punctum situated on the lacrimal papilla, which unite to form common canaliculus and drains

Financial or Other, Competing Interest: None.

Submission 03-05-2017, Peer Review 01-06-2017,

Acceptance 07-06-2017, Published 03-08-2017.

Corresponding Author:

Dr. N. Gopinathan Pillai,

Associate Professor,

Department of Otorhinolaryngology,

Pushpagiri Institute of Medical Sciences and

Research Centre, Thiruvalla.

E-mail: gopidrent@gmail.com

DOI: $10.14260 /$ jemds $/ 2017 / 978$ into lacrimal sac. From there fluid transmits into the inferior meatus of the nose through the nasolacrimal duct. Nasolacrimal duct opening lies about $1.5 \mathrm{~cm}$ posterior to the anterior end of inferior turbinate. This opening is guarded by Hausner's valve. Lacrimal gland is situated in the superolateral part of orbit and upper eyelid. About 12 slender ducts opens in the superior fornix of eye. Lacrimal canaliculi are 2 slender tubes of about $1 \mathrm{~cm}$ length, begins at the lacrimal punctum situated on the summit of lacrimal papilla. It runs medially and opens into the lacrimal sac, posterior to medial palpebral ligament. Lacrimal sac is lodged in the lacrimal groove and it is $1 \mathrm{~cm}$ long and $0.5 \mathrm{~cm}$ wide. Its upper end is blunt, and lower end continuous as nasolacrimal duct. Duct is $1.5 \mathrm{~cm}$ long and $0.5 \mathrm{~cm}$ wide; it passes downwards through the nasolacrimal canal to end in the inferior meatus of nose. Hausner's valve, it is a mucosal fold on the medial side of the nasolacrimal duct opening and acts as a flap valve, prevents air and secretions being blown up.

\section{Aetiology of Nasolacrimal Duct Obstruction}

The nasolacrimal duct obstruction is the commonest cause of epiphora. 
The causes of Nasolacrimal Duct Obstructions are many They are-

1. Chronic dacryocystitis: It is the commonest cause of epiphora. Chronic dacryocystitis leads to obstruction of the duct by contracture or stricture. Acute exacerbation of chronic dacryocystitis is also common. Tuberculous infection of the nasolacrimal sac must be excluded. Chronic infection may also lead to formation of dacryoliths and subsequent obstructive signs and symptoms.

2. Congenital defects like nasolacrimal duct atresia and fistula are also common. The line of fusion between lateral nasal wall and maxillary process followed by its canalisation may be incomplete or fistulous tract may develop.

3. Trauma: Fracture of the ascending process of maxilla or lacrimal bone following road traffic accident or surgery may sever or compress the nasolacrimal duct, or sac may lead to stenosis or atresia.

4. Benign tumours like nasal polyp may cause absorption of ethmoidal bone and obstruction of sac by pressure.

5. Neoplasms of maxillary sinus, ethmoidal sinus may press or invade the sac or duct. Lacrimal sac neoplasms are not uncommon. Rodent ulcer of inner canthal region and subsequent scarring after irradiation may cause obstruction of nasolacrimal sac or duct.

6. Granulomatous conditions such as sarcoidosis, Wegener's granulomatosis ${ }^{5}$ may also compress the sac or duct.

\section{Clinical Features}

Epiphora is the cardinal symptom of obstruction. Pressure over the sac produces a flow of fluid or mucopurulent fluid or pus from the puncta when infection is present. The sac may be palpable if distended by retained fluid or pus. It is tender during an acute exacerbation of infection. Then it may present as mass near the medial canthus. Benign tumours are most frequently squamous papillomas. Lacrimal sac tumours may be malignant in $50 \%$ of cases. The majority of these cases are squamous cell carcinoma.

\section{Management of Chronic Dacryocystitis}

In the middle ages, treatment for chronic dacryocystitis was drainage of abscess externally and extirpation of the lacrimal sac. In late $18^{\text {th }}$ century modern techniques of draining the tear sac into the nose were introduced, whether it is by the external or endonasal approach.

The surgical procedure for the above conditions are dacryocystectomy (Surgical removal of entire lacrimal sac), and dacryocystorhinostomy. DCR is the accepted procedure nowadays. It can be done externally or through endonasal route. Classical external approach was described by Adeo Toti in 1904.5 ENT surgeons prefer endonasal endoscopic DCR. Intranasal DCR was first described by West and Halle in $1910^{6}$ using microscope for visualisation. The advent of endoscope with camera and monitor has revolutionised endoscopic DCR. McDonogh and Meiring did first endoscopic endonasal DCR in 1989. ${ }^{7}$ Endoscopic DCR enables the surgeons to identify any associated intranasal causes such as high septal deviation, adhesions, concha bullosa, ethmoidal sinusitis, etc. and it can be corrected at the same time of endoscopic DCR surgery. In failed external DCR cases and revision cases, endonasal endoscopic DCR is the choice of management.

\section{External DCR}

It involves a 12-mm long skin incision on the side of the nose to gain access to lacrimal sac. After detaching medial canthal ligament, the periosteum over the lacrimal crest is divided to enter lacrimal fossa. An osteotomy is done in the ascending process of maxilla and lacrimal bone and exposes nasal mucosa. The nasal mucosa is incised vertically to create the flaps, followed by the lacrimal sac. The lacrimal sac flaps are sutured to posterior nasal mucosa to create a direct passage between sac and nose. A silicone tube passed through the sac and kept into the nose to keep the passage open. The anterior lacrimal sac flap is sutured to anterior nasal mucosal flap. Tube is removed after 6 - 8 weeks postoperatively, endonasally.

Eighty percent of the lacrimal pathways are inside the nose. So DCR may be performed via an endonasal approach. Therefore, endoscopic DCR is a promising approach to the obstruction or stenosis of the lacrimal sac (Saccal obstruction) or nasolacrimal duct (Post-saccal obstruction). Congenital dacryocystoceles, unresolved congenital nasolacrimal duct obstructions are indications for endonasal surgery. Presaccal stenosis are not suitable for an endoscopic procedure. Acquired obstruction of the lacrimal pathways is a common problem of elderly female patients, which can be corrected by endonasal endoscopic DCR. The best method to assess the site of obstruction consists of probing the lacrimal pathway and syringing. Fluorescein dye test (Jones I and II) or dacryocystography are no longer performed routinely. CT scan may be used to assess the dacryocystoceles, but it is not routinely employed. Lacrimal duct cyst (Dacryocystoceles) may present as a unilateral or bilateral bluish paranasal masses with an intranasal component and nasal obstruction symptoms. Lacrimal sac neoplasms are usually non-tender, but usually present as epiphora. Dacryoadenitis is the inflammation of lacrimal gland, and present as painful swelling near the upper eyelid laterally. Dacryocystitis present as a swelling near the medial canthus of eye and pressure over the lacrimal sac express purulent secretions from lacrimal punctum.

Diagnostic procedures commonly done are syringing of the passage to test the patency of nasolacrimal apparatus, diagnostic nasal endoscopy and radiography. CT scan is done to exclude causative factors in the sinuses.

\section{MATERIALS AND METHODS}

This prospective study was done on 34 patients with chronic dacryocystitis between January 2012 and August 2016 who presented with epiphora, lacrimal regurgitation and painful swelling below the medial canthus of the eye. Diagnosis was made by doing regurgitation test, lacrimal sac syringing and diagnostic nasal endoscopy.

All cases were operated under general anaesthesia. The nasal cavities were packed with cottonoids soaked in $4 \%$ xylocaine with 1: 100000 adrenaline for 10 minutes before the procedure. Then the packs were removed. With the help of $0^{0}$ endoscope, mucosa of the lateral wall of the nose anterior to the uncinate process and the middle turbinate were infiltrated with $2 \%$ xylocaine with 1: 20000 adrenaline. Using a sickle knife, a semilunar incision was made on the 
lateral wall from the anterior end of the axilla of the middle turbinate down to the inferior turbinate after identifying the maxillary line. Mucosal flap was raised and reflected backwards. Ascending process of the maxilla and lacrimal crest were identified. With the help of Kerrison punch, the medial bony wall covering the sac was removed. Removal was started from the maxillary line. The medial wall of the lacrimal sac movement can be appreciated by applying gentle pressure over the eyeball. Then the medial wall of the sac was incised and enlarged with Tru-Cut forceps. Upper part of the nasal mucosa was trimmed, while the lower part was repositioned back to cover the raw bone. Syringing with normal saline was done $4-5$ times. The free flow of saline from the newly created stoma was considered as successful criteria for the surgery. Postoperatively, oral antibiotics was given for one week along with nasal decongestants, saline nasal spray to prevent crusting and antibiotic eye drops for 3 - 4 weeks. All the patients were followed for endoscopic removal of crusts and to check the patency of new stoma by syringing weekly for one month and then monthly for three months and then at six months and one year.

\section{RESULTS}

There were 34 patients in the present study. Their ages ranged from 13 - 83 years. Commonly affected age group is 40 - 83 years. The mean age of the patient was 35 years. Females (26) were more commonly affected than the males. ${ }^{8}$ Cases with pre-sacral block, previous lacrimal trauma were excluded from the study. Patients who required other nasal procedures like septoplasty, conchoplasty, and clearance of agger nasi cells were included in the study. Three cases have bilateral dacrocystitis; 18 patients have left-sided complaints and 13 patients have right-sided complaints. So $91 \%$ of patients have unilateral symptoms, whereas $9 \%$ have bilateral symptoms; 24 patients presented with persistent watering from affected eye, 6 patients with mucopurulent discharge and 4 with swelling and mucopurulent discharge on applying pressure.

In more than $86 \%$ of patients, mucus or pus were obtained after lacrimal sac incision. Dacryoliths were not encountered. Lacrimal sac neoplasms were also not encountered. The histological studies of the medial lacrimal sac wall showed chronic inflammation with different degrees of cellular infiltration. In 1 case, inflammatory process extends to the medial lacrimal bone.

\begin{tabular}{|c|c|c|}
\hline Sex & No. & Percentage \\
\hline Male & 8 & $23.5 \%$ \\
\hline Female & 26 & $76.5 \%$ \\
\hline Age range & $13-83$ yrs. & \\
\hline Mean age & 35 yrs. & \\
\hline Laterality & & Percentage \\
\hline Left & 18 & $53 \%$ \\
\hline Right & 13 & $38 \%$ \\
\hline Bilateral & 3 & $9 \%$ \\
\hline $\begin{array}{l}\text { Additional procedures } \\
\text { Septoplasty, Conchoplasty } \\
\text { and Ethmoidectomy }\end{array}$ & 9 & $\begin{array}{c}\text { Percentage } \\
26 \%\end{array}$ \\
\hline
\end{tabular}

\begin{tabular}{|c|c|c|c|}
\hline $\begin{array}{c}\text { Serial } \\
\text { No. }\end{array}$ & Clinical Features & $\begin{array}{l}\text { No. of } \\
\text { Cases }\end{array}$ & $\%$ \\
\hline $\begin{array}{l}1 . \\
2 . \\
3 .\end{array}$ & $\begin{array}{c}\text { Persistent watering from the eye } \\
\text { Mucopurulent discharge } \\
\text { Swelling with mucopurulent } \\
\text { discharge } \\
\end{array}$ & $\begin{array}{c}24 \\
6 \\
4\end{array}$ & $\begin{array}{c}70.5 \% \\
17.5 \% \\
12 \%\end{array}$ \\
\hline Total & & 34 & \\
\hline
\end{tabular}

Endoscopic septal correction were performed in 5 cases for high anterior deviation of the nasal septum to gain adequate access and exposure. Concha bullosa were addressed in 3 cases, and agger nasi cells in 1 case. There were no major intraoperative complications like diplopia, orbital fat prolapse or epistaxis or minor complications like cheek ecchymosis or subcutaneous emphysema were observed. All patients were strictly advised not to blow their nose postoperatively for 1 week. After that they are encouraged to blow their nose to clear the blood clots. Patients were followed for 6 months to 1 year following surgery by syringing the sac to assess the patency of the sac and patient satisfaction; $97 \%$ of patients were fully satisfied and 1 patient with partial block was not fully satisfied (3\%). The scarring, fibrosis and synechia were not observed in the present study. Partial obstruction may be due to stenosis of the new stoma.

The postoperative evaluation was done objectively and subjectively. Objective evaluation was done by syringing and nasal endoscopy. Subjective evaluation includes "yes" or "no" answer to the questions of epiphora, recurrence, painful swelling has been resolved and cosmetic appearance.

\begin{tabular}{|c|c|c|c|c|}
\hline $\begin{array}{c}\text { Serial } \\
\text { No. }\end{array}$ & $\begin{array}{c}\text { No. } \\
\text { Cases }\end{array}$ & $\%$ & Syringing & $\begin{array}{c}\text { Symptomatic } \\
\text { Outcome }\end{array}$ \\
\hline 1. & 33 & $97 \%$ & $\begin{array}{c}\text { Patent } \\
\text { Partial } \\
\text { block }\end{array}$ & $\begin{array}{c}\text { Completely satisfied, } \\
\text { Partially satisfied }\end{array}$ \\
\hline 2. & 1 & $3 \%$ &
\end{tabular}

Table 3. Results of Endoscopic Endonasal DCR after 6 Months - 1 Year

\section{DISCUSSION}

The search for an alternative to external DCR approach is motivated by the desire for improved success rate, better anaesthetic result and better compliance by the patient. The endonasal endoscopic DCR is a one-staged procedure that permits correction of associated pathologies such as chronic sinusitis, deviated nasal septum which may lead to dacryocystitis. Many newborns suffer from congenital nasolacrimal duct obstruction, post-natally there is a high tendency of spontaneous resolution within the first 10 months of life. Malformations of lacrimal pathways are more common in children. Technically, the narrowness of nose is a challenge for endonasal DCR in paediatrics group, but the results has no change or at par with adult DCR. Nasolacrimal duct intubation may avoid DCR. Presaccal stenosis or stenosis of the canaliculi are not a contraindication for DCR, as it prepares the site for subsequent positioning of a Lester-Jones tube.

In external DCR, there is an external nasal scar and the possibility of injury to medial canthal ligament and orbicularis muscle. In endoscopic DCR there is no external incision, hence no pathological nasal scar, no injury to medial 
canthus and orbicularis oculi muscle. So, it preserves the pumping mechanism of orbicularis muscle. Active infection of the lacrimal system is not a contraindication to intranasal DCR, as it drains mucopus into the contaminated nasal cavity. The normal scarring produced after an external DCR makes revision procedure difficult and the final aesthetic and functional results are not good. So, revision cases endonasal endoscopic DCR is the choice of approach. The low rate of intraoperative and postoperative complications of endonasal endoscopic DCR made it more acceptable.

The aim of this study was to assess the success rate and patient satisfaction of the endonasal endoscopic DCR over external DCR; 3 - 4\% of patients attending the ophthalmology clinics complaints are excessive tearing. ${ }^{8}$ Chronic dacrocystitis is the most common cause of chronic excessive tearing. External DCR was the standard procedure for it in the past, but its failure rate ranges from $3-15 \% .^{3}$ If the access to the lacrimal sac is compromised by the other anatomical causes then it can be successfully managed by the endoscope, viz. deviated nasal septum, concha bullosa, prominent agger cells, ethmoiditis at the same sitting.

The success of endonasal endoscopic DCR depends upon the thorough understanding of endoscopic anatomy and location of lacrimal sac, adequate removal of frontal process of maxilla and precise opening of the medial wall of the lacrimal sac. Endoscopic endonasal approach can identify the intranasal causes of DCR failure and avoid external facial scar. The reported success rate of endoscopic endonasal DCR vary from $90-98 \%$ and it is greater than external DCR. In our study, success rate and patient satisfaction was $97 \%$. Tsirbas and Wormald ${ }^{9}$ had only $89 \%$ success rate.

Endoscopic endonasal DCR avoids external incision, so cosmetically it becomes more acceptable. It preserves the pumping action of orbicularis oculi muscle. It can be performed in acute stage of infection as well as in revision cases of external DCR and avoid subsequent scarring. ${ }^{5}$ Umar et $\mathrm{al}^{10}$ highlighted the need for otolaryngologist to be routinely involved in the DCR surgery.

In this study from January 2012 to August 2016, we also found that 9 out of 34 patients needed concomitant endonasal procedure for associated sinonasal diseases to prevent recurrences. It also emphasises the necessity of association of otolaryngologist in endoscopic endonasal DCR. Ramakrishnan et al ${ }^{11}$ obtained $100 \%$ for anatomic patency and $93 \%$ for complete resolution of epiphora. In our study, we had $97 \%$ success rate and patient satisfaction. Application of mitomycin can antimetabolite, which reduces scarring was used following surgery by Selig et al. ${ }^{12}$ But they had success rate of only $87.5 \%$. In our study, we did not use mitomycin C, but with meticulous post-operative cleaning we found no scarring or crusting or granulation tissue formation and success rate was $97 \%$.

\section{CONCLUSION}

Endoscopic endonasal DCR overcomes all the drawbacks of external DCR namely external facial scar, impairment of pumping action of lacrimal system, distortion of medial canthus anatomy, inability to treat coexisting sinonasal diseases or anatomical compression of nasolacrimal system, it also avoids scarring and adhesions. So endoscopic endonasal DCR is a better alternative to external DCR with a success rate of $95-100 \%$. The introduction of mucosal flap to partly cover the lateral nasal wall provide fast healing, prevents granulation tissue formation, haematomas or ecchymosis of the cheek. Cosmetic and functional advantages make endonasal endoscopic DCR more popular and acceptable.

\section{REFERENCES}

[1] Tarbet KJ, Custer PL. External dacryocystorhinostomy. Surgical success, patient satisfaction, and economic cost. Ophthalmology 1995;102(7):1065-70.

[2] Whittet HB, Shun-Shin GA, Awdry P. Functional endoscopic transnasal dacryocystorhinostomy. Eye 1993;7(Pt 4):545-9.

[3] Cokkeser Y, Evereklioglu C, Er H. Comparative external versus endoscopic dacryocystorhinostomy: results in 150 patients. Otolaryngol Head neck surg 2000;123(4):488-91.

[4] Sprekelsen MB, Barberan MT. Endoscopic dacryocystorhinostomy: surgical technique and result. Laryngoscope 1996;106(2 Pt 1):187-9.

[5] Toti A. Nuovo methodo conservatore di cura radical delle suppurazioni eroniche del sacco lacrimale (dacriocistor inostomia). clin Mod Firenze 1904;10:385-7.

[6] West, Halle. Intranasalen operation am tranen sack. Arch Laryngorhinol 1914;28:256-66.

[7] McDonogh M, Meiring JH. Endoscopic transnasal dacryocystorhinostomy. J Laryngol Otol 1989;103(6):585-7.

[8] Welham RA. Clinical Ophthamology. In: Miller S. (Edr) IOP Publishing Ltd. Bristol (Indian EDN) 1997:391441.

[9] Tsirbas A, Wormald PJ. Endonasal dacryocystostomy with mucosal flaps. AM J Ophthamol 2003;135(1):7683.

[10] Dalgleish R. Idiopathic acquired lacrimal drainage obstruction. Br J Ophthalmol 1967;51(7):463-8.

[11] Ramakrishnan VR, Hink EM, Durairaj VD, et al. Outcome after endoscopic dacryocystorhinostomy without mucosal flap preservation. Am J Rhinol 2007;21(6):753-7.

[12] Selig YK, Biesman BS, Rebeiz EE. Topical application of mitomycin $\mathrm{C}$ in endoscopic dacryocystorhinostomy. Am J Rhinol 2000;14(3):205-7. 